\title{
A Arte Mais Além de Auschwitz Sobre a interpretação da teoria estética adorniana feita por Christoph Menke
}

\author{
Maurício Chiarello*
}

Resumo: Poucos são os comentários da Teoria Estética adorniana que atinam com seu espinho na carne mais dolorido. Mesmo os mais bem intencionados não raro recaem numa espécie de esteticismo ao atribuir a negatividade exercida pela obra de arte exclusivamente a seu próprio medium. Menospreza-se assim o entrelaçamento, vital para toda obra de arte sobretudo depois de Auschwitz, que se dá entre expressão, dor e morte, assim como a negatividade que delas decorre. É o que talvez seja emblemático na interpretação ora em questão de autoria de Christoph Menke.

Palavras-chave: estética - negatividade - expressão - dor - morte

"Ist die Sprache der Natur stumm, so trachtet Kunst das Stumme zum Sprechen zu bringen..." "Das Lückenlose, Gefügte, in sich Ruhende der Kunstwerke ist Nachbild des Schweigens, aus welchen allein Natur redet."

T. W. Adorno, Ästhetische Theorie.

Antes de mais nada, seria preciso dizer que a interpretação da teoria estética de Theodor W. Adorno presente em Die Souveränität der Kunst ${ }^{1}$ é sem dúvida preciosa sob um aspecto: pelo esclarecimento que nos proporciona quanto aos limites da crítica habermasiana endereçada àquela teoria

\footnotetext{
* Doutorando do Departamento de Filosofia - IFCH - Unicamp e bolsista do CNPq.
} 
estética. Crítica esta que, como é notório, não se restringe à obra adorniana, mas se estende aos autores do "discurso filosófico da modernidade", integrantes de uma tradição que vai de Nietzsche a Adorno. Para ir direto ao ponto central da argumentação de Menke, bastaria dizer que, pare ele, Adorno concede à arte um papel proeminente em relação à razão (dos discursos não estéticos) não porque, como pretende Habermas, a arte apareça como um "au-delà" portador da solução das aporias da razão moderna, mas, ao contrário, porque somente ela, a arte, é capaz de confrontar a razão com problemas mal resolvidos. Não se sustenta, assim, o juízo de Habermas que associa Adorno a uma tradição romântica de resolução estética das aporias da razão; sua teoria estética é autenticamente moderna, na medida em que compreende a negatividade absoluta da experiência estética como um perigo a ser evitado para o jogo efetivo de interação das distintas esferas de autonomia da razão.

Se a arte é, para os românticos em geral, uma instância transracional na qual problemas prévios de domínios não estéticos encontram solução, para Adorno, muito diversamente, ela aparece como um catalisador de problemas que, sem ela, não poderiam vir a tona e sequer ser pensados: "Se nos livramos da influência da estética romântica, compreendemos que o caráter aporético da razão não é anterior à experiência estética, e que sequer podemos formulá-lo sem pressupor esta última: é a experiência estética da negatividade, realizada de forma soberana, que revela uma aporia interna, insolúvel, em nossos discurso eficazes"(Menke 5, p. 286). Assim, a dimensão aporética que Adorno descobre atuante em nossos discursos e práticas racionais não poderia vir à luz senão através da negatividade estética. Em Derrida, sim, Menke acredita poder diagnosticar uma forma invertida de romantismo, a saber, no modo como aplica ao domínio extra-estético a experiência soberana da negatividade estética: "O programa de Derrida constitui, contudo, um retorno do romantismo pelo fato de caracterizar a experiência estética, tornada a instância de um conhecimento exclusivo, como o meio não mais de reconciliação, mas de um adiamento indefinido, ou de uma negação irredutível" (Idem, p. 287-8). Tal como os românticos, Derrida sobrecarregaria a arte de pretensões desmesuradas.

Quando Adorno concede à experiência estética um estatuto privilegiado, evita torná-la absoluta, de modo a sustentar a tensão preexistente entre ela e as demais dimensões autonomizadas das razão. De sorte que Menke não compartilha o juízo de Habermas segundo o qual o estatuto adorniano 
da arte significaria um retorno a um estado de indiferenciação das esferas de autonomia da razão, no qual os âmbitos da verdade, da moral e da arte comporiam um só todo; muito pelo contrário, ele encerraria um projeto que poderia concorrer perfeitamente com o de Habermas na proposta de correlação (ou integração?) daquelas distintas esferas de autonomia.

Mas se assim é, perguntamo-nos então em que diferiria o projeto habermasiano daquele que poderia fazer-se presente na obra de Adorno, desde que bem lida, ou melhor, o que exatamente desagradaria Habermas na teoria estética de Adorno? A resposta de Menke não se faz esperar: "Mas nós vimos, na primeira parte, a que preço se paga esta idéia de uma reintegração da experiência estética; é, com efeito, o mesmo programa que a estética hermenêutica já defendia, tão enfaticamente, contra o esteticismo e sua insistência sobre o caráter inassimilável da experiência estética: 'reconhecer' deste modo a arte é reduzir a experiência estética, segundo uma 'heteronomia latente', a um ato de compreensão por identificação, que não mais se encontra em oposição com os discursos não estéticos, mas que lhes corresponde e lhes completa. Ora, se toda reintegração no quadro do mundo vivido priva necessariamente a experiência estética de seu conteúdo negativo, é que a autonomia e o reconhecimento não se deixam combinar como prometido" (Idem, p. 291). Em duas palavras, aquilo que então desagrada a Habermas não é senão o reconhecimento da legítima autonomia da arte e da efetiva negatividade que dela decorre para a teoria.

Muito embora esta interpretação, que nos oferece Menke, da teoria estética de Adorno pareça-me justa no que tange ao lugar ocupado pela arte no discurso filosófico da modernidade, penso que seria preciso questionar o que se me afigura o calcanhar de Aquiles de sua leitura, qual seja, o da desqualificação, face à negatividade da experiência estética, da experiência da morte e da loucura como variantes não-estéticas da negatividade total. Num certo sentido, ao que me parece, Menke acaba por conceder à experiência estética uma negatividade incondicional, o que faz com que sua análise recaia numa espécie de esteticismo. A este respeito, seria oportuno perguntar desde já: onde fica o caráter transfigurador, encobridor, até mesmo macabro, que Adorno tão insistentemente acusa na aparência estética? Poderia Menke, de algum modo, admitir a afirmação de Adorno, que tanto recende a Nietzsche, segundo a qual as obras de arte vivem da morte, ou melhor, nutrem-se da morte? (cf. Adorno 1, p. 201). Em algum momento reconhece ele que a reconciliação encerrada na arte é a da morte e do silên- 
cio? Se, como gosta de dizer Menke, a negatividade estética representa um problema incontornável e até mesmo uma ameaça permanente para toda sorte de razão discursiva (discurso racional) - com o que muito me apraz concordar enfaticamente -, não se pode ignorar, por outro lado, que a própria representação artística figura um problema, e justamente enquanto representação, isto é, reconciliação ilusória, promessa fraudada de felicidade.

Parece-me, igualmente, que Menke não reconhece como seria preciso o conteúdo de verdade da obra de arte, este real que involuntária e inopinadamente manifesta-se no espaço irreal da representação artística, não fosse o qual o próprio caráter enigmático da obra, antes alegórico que simbólico, refratário a toda interpretação definitiva, não teria lugar. É só porque a obra apela para um sentido oculto que se furta, a algo, portanto, que não se contenta com ela mesma, com sua matéria literal, clamando por uma interpretação jamais satisfatória, é só por isso, dizia, que ela pode perturbar e desconcertar. Certo, ela não é nem mero choque nem mera epifania, no sentido de que aquilo que nela se dá a ver simultaneamente se furta, mas daí dizer que "a própria obra é o que aparece" é trair o conteúdo de verdade disto que nela se oculta. Epifania, sim, mas de algo que hesita em se exprimir, assombroso, medonho, que por isso não pode calar, que pede a palavra, e paradoxalmente se cala no exato momento em que logra articular um sentido. Para silenciar o por vezes prolixo discurso de Menke bastaria talvez a concisa frase de Adorno, de inegável ressonância nietzscheana, segundo a qual é mais certo que o belo tenha surgido do feio do que o contrário (cf. Adorno 1, p. 81). Pois sua análise faz vista grossa para o entrelaçamento, vital para toda obra de arte, que se dá entre expressão, dor e morte.

Recapitulemos brevemente as páginas deste estudo em que Menke intenta sustentar, contra Adorno, que é a própria experiência estética, e não a experiência da morte invocada por Adorno, que constitui a instância por excelência de negatividade total de nossos discursos, negatividade esta que, para ele, se põe como o próprio fundamento da dialética negativa. Menke julga ser preciso desbaratar aquilo que, nas suas palavras, designa como sendo "a tese adorniana segundo a qual a experiência da morte constitui um problema insuperável para nossos esquemas de interpretação do mundo e de nós mesmos" (Menke 5, p. 258). Ora, a experiência da morte invocada por Adorno, notadamente em suas "Meditações sobre a metafísica" da Dialética Negativa, não é uma experiência empírica qualquer, mas a experiência assombrosa da morte projetada a partir da sombra hedionda de 
Auschwitz. E o que ela põe radicalmente em questão, como se compreende, é muito mais do que a mera "possibilidade de nossos discursos" (ou de escrever poemas depois de Auschwitz), mas de toda nossa existência. É alias estarrecedora a ligeireza com que Menke passa por cima da carga de sofrimento insuportável desta "experiência", reduzindo-a a um evento da ordem da experiência empírica, e portanto insuficiente para precipitar nossos discursos numa crise insuperável: "Para nós que nos interessamos pela estrutura da fundação genealógica da dialética negativa, a questão não é tanto a de determinar a quais experiências empíricas Adorno se refere, mas a de saber se é possível explicar satisfatoriamente a própria idéia de uma experiência que precipitaria numa crise insuperável os discursos que se vêm com ela confrontados" (Idem, p. 255). Eis portanto a morte em Auschwitz, entendamos, a morte que ronda desde então a existência no mundo do poder total e totalitariamente instituicionalizado, esta morte monstruosa precisamente por sua absoluta insignificância (tão banal quanto um gole d'água que se toma, um pé de couve que se corta), ei-la equiparada à "experiência de um fenômeno cuja natureza geral e inevitável é incontestável" (Idem, p. 256). Tendo deste modo purificado e generalizado a experiência da morte, torna-se evidentemente fácil para Menke recusar-lhe a força de negatividade capaz de colocar em questão a totalidade de nossos discursos, e não só deles: "Ao que me parece, contra a argumentação desenvolvida por Adorno nas 'Meditações sobre a metafísica', é preciso responder a estas questões pela negativa. Recuso a maneira pela qual Adorno funda genealogicamente as reivindicações absolutas, irrealizáveis, da metafísica tradicional sobre a experiência moderna da morte, não em razão do argumento genealógico em si mesmo, mas sim do estatuto que confere a esta experiência. O que contesto é que se faça da morte a instância de uma negatividade total" (Idem, p. 256). Segundo sua argumentação, para acompanhar-lhe um pouco mais de perto, não poderia ser exterior ao meio discursivo uma experiência cuja negatividade se pretendesse total a este meio, isto é, capaz de arruinar nossos discursos e comprometer seus resultados, capaz de, enfim, instaurar uma crise insolúvel no seu âmbito. Para tanto, seria preciso que uma tal experiência fosse ela própria representável de forma discursiva. Ora, para Menke, a experiência estética integra a morte nela mesma, permanecendo, por isso mesmo, incólume a ela. Imune a este poder não-discursivo extremo, o discurso estético, este sim, exerce soberano seu poder dissolvente sobre todas as demais modalidades discursivas: "A experiência estética da negatividade 
é uma negação total de todos os nossos discursos [...] porque - contrariamente à experiência da morte - ela não incide somente sobre a pertinência de nossos discursos, mas também sobre seu funcionamento eficaz" (Idem, p. 269). O mesmo se aplicaria, aliás, à experiência da loucura. Por não participar da ordem discursiva a qual se opõe, sua negatividade falha como falha aquela do discurso cético: "A loucura não constitui um problema para nossos discursos, visto que no exato momento em que ela se produz, ela perde o estatuto de uma experiência possível e, daí, seu poder de contestação" (Idem, p. 272). Penso que não seja preciso dizer mais. Para Menke, a arte esvoaça ao redor da chama da verdade determinada a não se queimar. Envolve a morte com suas palavras sem jamais perder a palavra; faz rodeios em torno dos infortúnios mais cruciantes sem perder o sorriso dos lábios. Ela não passa simplesmente ao largo da morte, ela se faz passar pela própria morte, e disso justamente extrai a negatividade inexorável que lhe outorga Menke. Para ele, a esfera da estética fecha-se sobre si mesma em sua suprema soberania, inexpugnável de fato como o castelo senhorial de Kierkegaard, onde a indiferença reinante compactua, de forma sublime, com todo insano poder de destruição e de morte. De sorte que, da distância contemplativa de sua imagem sem fundo, ficamos de fato a nos perguntar o que tanto ela teria a dizer com toda sua negatividade desmanteladora de nossos discursos.

Esta impassibilidade assim expressa ante o "fenômeno da morte", aliás "de natureza geral e incontestável", não é ela mesma sintomática da indiferença a que se chegou frente à vida individual? Curioso, ademais, como o discurso põe-se, para Menke, acima desta realidade dolente - e especialmente o discurso estético, por ele valorizado pela força da negatividade exercida sobre todas as demais formas de discurso não-estéticos. Não recairia no vazio esta negatividade total concedida aos discursos estéticos e recusada expressamente à experiência da morte e do sofrimento? Não procuraria, esta leitura de Menke, retirar da teoria estética adorniana o espinho na carne mais dolorido, redundando assim num esteticismo inócuo quanto mais insiste em sua negatividade soberana?

Para não ser injusto em demasia com esta interpretação da teoria estética adorniana, seria contudo preciso ressalvar que toda sua análise procura concentrar-se no efeito crítico-dissolvente que a dimensão estética exerce sobre as demais esferas da cultura, evidenciando, assim, sua negatividade soberana. Assim é que Menke não concede a devida importância à irresistível 
necessidade da decifração do enigma das obras, ou, por outras, ao conteúdo de verdade apenas acessível por meio da reflexão filosófica: "Ao exigir a solução, o enigma remete para o conteúdo de verdade, só acessível mediante reflexão filosófica. Isto, e nada mais, é o que justifica a estética" (Adorno 1, p. 193) ${ }^{2}$. Esta é, afinal, a questão central de toda estética enquanto filosofia da arte. Julgá-la-ia Menke desprovida de sentido?

Atribuindo à dimensão estética uma negatividade neste sentido soberana, Menke mostra-se refratário ao tema, tão essencial à arte moderna, da participação no sombrio. Soa estranho, para ele, sustentar que a arte carregue uma espécie de culpa pelo espaço encantatório de beleza e reconciliação que lhe é próprio, e que um desejo paradoxal de expiação alimente o gosto pelo negro do luto e pelo regresso ao silêncio.

Lembremos, contra esta leitura afinal estetizante, a passagem da $\mathrm{Te}$ oria Estética em que se afirma serem as obras de arte aparições no sentido mais expressivo do termo, isto é, aparições de um outro, quando se evidencia o irreal de sua irrealidade (cf. Adorno 1, p. 123). "Em toda obra de arte genuína aparece o que não existe" (Idem, p. 127). Trata-se de um "mais" por ela artificiosamente laborado, malgrado o que dela distinto, um outro, enfim, muito embora por ela mediado (cf. Adorno 1, p. 122). Na secção sobre o caráter enigmático, lemos ainda: "O enigmático das obras de arte é o seu estar separado. Se a transcendência nela estivesse presente, então seriam mistérios, não seriam enigmas" (Idem, p. 191). Ao sortilégio da arte, a este campo de encantamento mágico do qual Menke parece incapaz de se libertar, exaltando o enigma pelo enigma, a isto se opõe justamente o conteúdo de verdade enquanto desvendar de um enigma que anseia pela redenção (e o que de forma alguma se resolve perde seu caráter enigmático). Como escreve Adorno, em suas "Anotações sobre Kafka": "Ela [a obra de Kafka] não se exprime pela expressão, mas pelo repúdio à expressão, pela ruptura. É uma arte de parábolas para as quais a chave foi roubada; e mesmo quem buscasse fazer justamente desta perda a chave seria induzido ao erro, na medida em que confundiria a tese abstrata da obra de Kafka, o obscuro da existência, com seu teor. Cada frase reclama: 'Interprete-me'; e nenhuma frase tolera a interpretação" (Adorno 3, p. 241).

A propósito, o conceito adorniano de expressão, tão decisivo para sua teoria estética, vê-se praticamente menoscabado por Menke. E, no entanto, é justamente graças à expressão que, segundo Adorno, a experiência não estética inscreve-se mais profundamente nas obras: "der Ausdruck, 
durch den die nichtästhetische Erfahrung am tiefsten in die Gebilde hineinreicht" (Adorno 1, p. 169). Ora, em Menke, o caráter enigmático da obra gira em torno de si mesmo e não se abre à expressão. Aliás, em algum momento a parolagem de Menke põe-se à altura de compreender a vizinhança extrema da expressividade da obra com seu silenciar? "Vielleicht ist aller Ausdruck nächstverwandt dem Tranzendierenden, so dicht am Verstummen [...]" (Idem, p. 123). O que, com certa liberdade poética, poderíamos traduzir: "Talvez toda expressão, intimamente aparentada ao transcendente, esteja de tal forma apegada ao silenciar [...]". A obra deve calar fundo para deixar falar um outro, ainda que isto somente graças às suas palavras; deve saber calar para que no seu silenciar possa vir a exprimir-se um outro cujo falar não se confunde com o seu, cuja voz não é a sua. Deve querer-se finita, assumir sua transitoriedade, não aspirar a durar mais que o fulgor de um fogo de artifício, o clarão de uma estrela cadente, para só assim sonhar perenizar, em lugar de si mesma, o transitório, aquilo que na realidade encontra-se condenado à desaparição. É assim que toda obra de arte desaparece no seu conteúdo de verdade: a promessa de realização da verdade que ela encerra é também a promessa de vir a livrar-se de seu invólucro de obra, desaparecendo enquanto constructo (cf. Adorno 1, p. 199).

$\mathrm{O}$ esteticismo da análise que aqui procuro denunciar já se anuncia, aliás, na tese formulada logo na abertura de seu estudo: "a verdadeira diferença estética, a diferença entre o estético e o não-estético, é a negatividade" (Menke 5, p. 17). Menke faz assim residir na própria autonomia da arte seu caráter de soberana negatividade, pretendendo destarte dirimir a ambivalência insolúvel que, segundo ele, caracteriza a experiência estética moderna, ora firmada com base em sua autonomia, ora com base em sua soberania. Como poderia a arte ser um discurso autônomo entre outros e, ao mesmo tempo, uma soberana subversão da razão de todos os discursos? Este o paradoxo configurado, sempre segundo Menke, pela "antinomia da aparência da experiência estética" adorniana, de acordo com a qual "é justamente a aparência (autônoma) da arte que constitui sua verdade (soberana)" (Idem, p. 11). Paradoxo que Menke julga necessário deslindar, clarificando as premissas de sua dupla determinação na tentativa de reconstruir, com vistas a sua resolução, a antinomia adorniana da estética. Mas Menke termina por fundar a negatividade da experiência estética, a soberania de seu potencial crítico, em sua própria autonomia. É esta autonomia soberana por si só, isto é, soberana em virtude de sua própria especificidade, que permite a Menke 
criticar as concepções românticas de soberania da arte, entre as quais inclui as teorias desconstrutivistas mais recentes. Mesmo que a desconstrução interna dos discursos não estéticos não se confunda de fato com mero irracionalismo romântico, ela trai um certo romantismo pela afirmação incondicional, no seu proceder, do potencial crítico da arte frente às demais modalidades de discurso racional - em duas palavras, pela pretensão de ultrapassar esteticamente a razão. Nas teorias desconstrutivistas, Menke acusa uma transgressão da esfera de competência que compromete o pressuposto de autonomia da experiência estética: "A arte é soberana não porque ela suprime a fronteira entre a experiência estética e os demais modos de experiência (afirmando-se como um para além da razão ou como uma decomposição da razão que se impõe de modo imediato à própria razão), mas sim porque, tendo sua validade fundada apenas sobre si mesma, ela constitui uma crise para o funcionamento de nossos discursos" (Idem, p. 13). Menke livra-se facilmente da recriminação de romantismo que poderia ser endereçada à soberania do domínio estético dizendo: à diferença de todos os demais domínios não-estéticos, este domínio, e só ele, é negatividade soberana em sua autonomia - assim como seu caráter aparente por si só constitui a expressão de sua verdade. Fácil ver, desde já, como aqui a esfera estética se fecha sobre si mesma e de forma auto-suficiente: a antinomia entre aparência e expressão das obras se resolve, pois, em favor do caráter inexoravelmente aparente da expressão. A expressão não seria, afinal, outra coisa senão aparência incapaz de se livrar de si mesma.

"A experiência estética libera assim uma insuperável negatividade na coisa negada, mas uma negatividade que não lhe pertence propriamente senão porquanto se faz objeto de uma experiência estética" (Idem, p. 42). A frase bem acusa o esteticismo em que recai o estudo de Menke ao procurar resolver a aporia entre aparência e expressão, esta aporia que, nas suas palavras, constitui a própria nervura central da teoria estética adorniana. Ele não chega a afirmar que a negatividade estética seja abstrata, isto é, não determinada na terminologia hegeliana. Mas bem reconhece que ela corre $o$ risco de se fazer de forma não imanente à própria coisa negada. $E$ isto porque, diferentemente do que ocorre no domínio extra-estético, no domínio estético a negatividade imanente à coisa negada (que somente descobrimos pelo ato da negação), esta negatividade, sublinha Menke, "não possui nenhuma forma de existência fora da experiência estética que lhe traz à luz" (Ibidem). Menke entende a negatividade das obras não na forma da expres- 
são que se desenha enquanto tentativa de compreensão - neste sentido subordinada à negatividade imanente à coisa -, mas antes na forma da aparência que é a própria negação contumaz desta tentativa, entendamos, fracasso inevitável de toda tentativa de compreensão: "Pode-se falar de forma pertinente da negatividade como conceito central da estética apenas se a experiência estética é uma negação de toda tentativa de compreensão, e, particularmente, daquela que se encontra necessária e especificamente nela inscrita" (Idem, p. 43). O imperativo de exprimir, contra Wittgenstein, o que não se pode falar, este imperativo cuja negatividade provém de algo que não pode calar, vê-se completamente despotencializado na análise de Menke. É esta própria impossibilidade de exprimir, de atinar em definitivo com o sentido de algo que nos concerne no mais fundo, e que no entanto nos escapa, que Menke eleva à negatividade por excelência da experiência estética. Não seria isto consignar força à impotência? Ou melhor, não seria isto relegar a arte a um jogo de aparências fundado na negação última de toda tentativa de compreensão, a um jogo até mesmo frívolo em que o anseio cogente pela expressão se reduz, afinal, ao jogo inarredável e infindável da aparência estética?

Duas observações ligeiras a este respeito: 1) seria Adorno tão cioso assim, como Menke pretende nos fazer crer, desta suposta autonomia consignada aos discursos estéticos? 2) Além do mais, não teria ele, Menke, reduzido a experiência estética a uma experiência ao fim e ao cabo discursiva, fechada por sua própria autonomia a determinações extrínsecas vitais a ela, justamente aquelas que escapam a seu "modo discursivo soberano", e cuja busca pode mesmo constituir, enquanto busca da expressão, a razão de seu vir à luz? Quando Menke afirma ser a soberana negatividade da experiência estética o fundamento da dialética negativa adorniana, não passa ele por cima do mais crucial, curto-circuitando os extremos? Pois a negatividade da dialética adorniana se deve, antes de mais nada, ao momento corporal, de prazer e de dor, que jaz esquecido em toda figuração espiritual. Sua força ela extrai, em última instância, dos vestígios sensíveis persistentes em toda forma de conhecimento racional. E se a experiência estética exerce efetivamente, enquanto experiência discursiva, alguma negatividade para a dialética negativa, é apenas na medida em que nela se reflete esta negatividade da sensibilidade segregada pelo entendimento. Seria preciso tornar a mencionar aqui aquela notável passagem da Dialética Negativa, tão clara e incisiva a este respeito? "Na dimensão do prazer e do desprazer 
imiscui-se o corporal. Toda dor e toda negatividade, motores do pensamento dialético, são a figura do físico reiteradamente mediada e muitas vezes tornada irreconhecível. [...] A componente somática lembra o conhecimento que a dor não deve ser, que deve passar" (Adorno 2, pp. 202-3). O motor da dialética negativa, como Adorno o assevera, é antes esta forma elementar de contradição, a dor, esta dor que teima em ser dissuadida pelas formas discursivas não-estéticas da identidade, e cuja expressão se inscreve nas obras de arte como linha de demarcação contra seu caráter aparente. Que as obras devam desaparecer juntamente com a miséria do mundo, é algo que deixa de fazer sentido para esta interpretação.

\begin{abstract}
Few are the comments on the Adornian "Aesthetic Theory" that are objective enough to get to the point, no matter how painful it might be. Even the most well intended often tend to a certain aestheticism by attributing the negativity of the work of art exclusively to its own medium. The weaving of the plot - which is vital to every work of art especially after Auschwitz and which is made present between expression, pain and death, as well as the negativity brought by them - is underestimated. And this is what may be emblematical in Christoph Menke's interpretation.
\end{abstract}

Key-words: aesthetic - negativity - expression - pain - death

\title{
Notas
}

${ }^{1}$ MENKE, Christoph. Die Souveränität der Kunst. Athenäum Verlag, 1988. Valemo-nos aqui, para as citações, da tradução francesa desta obra: La souveraineté de l'art: L'expérience esthétique après Adorno \& Derrida (trad. de Pierre Rusch), Armand Colin, Paris, 1993.

${ }^{2}$ Mais ainda: "O seu objeto [da estética] define-se enquanto indefinível, negativamente. Por isso, a arte necessita da filosofia que a interprete, para dizer o que ela não pode dizer, muito embora só através dela pode ser dito ao não dizê-lo" (Adorno 1, p. 113). 


\section{Referências Bibliográficas}

1. ADORNO, T. W. Gesammelte Schriften, Suhrkamp Verlag, Frankfurt do Meno, vol. 7 [Ästhetische Theorie], 1970.

2. . Gesammelte Schriften, Suhrkamp Verlag, Frankfurt do Meno, vol. 6 [Negative Dialektik], 1973.

3. Prismas: Crítica cultural e sociedade (trad. de Augustin Wernet e Jorge de Almeida), Ática, São Paulo, 1998.

4. MENKE, Christoph. Die Souveränität der Kunst. Athenäum Verlag, 1988.

5.

. La souveraineté de l'art: L'expérience esthétique après Adorno \& Derrida (trad. de Pierre Rusch), Armand Colin, Paris, 1993. 